ORIGINAL ARTICLE

\title{
Influencing sceptical staff to become supporters of service improvement: a qualitative study of doctors' and managers' views
}

\author{
R Gollop, E Whitby, D Buchanan, D Ketley
}

See editorial commentary, p 89

Qual Saf Health Care 2004;13:108-114. doi: 10.1136/qshc.2003.007450

See end of article for authors' affiliations .....................

Correspondence to: R Gollop, Research into Practice Team, NHS Modernisation Agency, St John's House, East Street, Leicester LE1 6NB, UK; rose.gollop@npat.nhs.uk

Accepted for publication 2 November 2003

\begin{abstract}
Objective: To explore scepticism and resistance towards changes in working practice designed to achieve service improvement. Two principal questions were studied: (1) why some people are sceptical or resistant towards improvement programmes and (2) what influences them to change their minds.

Methods: Semi-structured qualitative interviews were conducted with 19 clinicians and 19 managers who held national and regional roles in two national programmes of service improvement within the NHS involving systematic organisational changes in working practices: the National Booking Programme and the Cancer Services Collaborative (now the Cancer Services Collaborative Improvement Partnership).

Results: Scepticism and resistance exist in all staff groups, especially among medical staff. Reasons include personal reluctance to change, misunderstanding of the aims of improvement programmes, and a dislike of the methods by which programmes have been promoted. Sceptical staff can be influenced to become involved in improvement, but this usually takes time. Newly won support may be fragile, requiring ongoing evidence of benefits to be maintained.

Conclusions: The support of health service staff, particularly doctors, is crucial to the spread and sustainability of the modernisation agenda. Scepticism and resistance are seen to hamper progress. Leaders of improvement initiatives need to recognise the impact of scepticism and resistance, and to consider ways in which staff can become positively engaged in change.
\end{abstract}

C hange is a constant feature of healthcare organisations and the difficulties associated with managing it are well acknowledged. ${ }^{1}$ They relate in part to the culture and history of the organisation, and to the people who work within it. Improving the quality of care through changing the way in which it is delivered is a goal shared by many healthcare organisations. The National Health Service (NHS) in England is currently embarked on a major programme of reform and modernisation, also known as the improvement agenda (box 1). It is underpinned by the expectation that staff will embrace change in order to improve services for patients. In particular, this includes the involvement of senior staff, both clinical and managerial. ${ }^{23}$

However, scepticism and resistance to organisational change within healthcare systems is recognised as a real barrier to progress. It has been claimed, for example, that resistance by doctors towards improvement initiatives is common across all countries and health systems. ${ }^{45}$ Locock suggests that, even though professionals value innovation and experimentation in their clinical lives, their past experience of change in the NHS gives them little reason to believe that it will improve either the quality of care or their own working lives. ${ }^{6}$ She notes that clinical resistance proved to be a major obstacle for the UK re-engineering pilots of the mid-1990s. ${ }^{3}$

Managing scepticism and resistance in positive ways is an essential part of the process of gaining support for change. Understanding the psychology of how people are influenced to change, and the stages they pass through during the process, is recognised as being particularly important. ${ }^{78}$ Promoting engagement with change by creating attraction and being prepared to explore the rationality of others' points of view is a framework that is also advocated.' Although resistance to change in health care is often interpreted in negative terms, research into broader organisational change has demonstrated its value in a number of ways. The presence of staff who challenge and question proposed change is seen by some as healthy and to be encouraged. ${ }^{10}$ Resistance can lead to a search for better methods that encompass conflicting opinions. ${ }^{11}$ Fostering a commitment to improvement principles at an early stage of career development can also help to create an environment where change is viewed as a challenge rather than a threat. Within health care it has been argued that educating undergraduate medical students in the principles and practice of continuous quality improvement would assist in this respect. ${ }^{12}$

In describing opposition to change within health care, the terms "scepticism" and "resistance" can be described as natural language labels representing a continuum of attitudes and behaviours. These range from silent doubt and low energy support through to vocal cynicism and passive or active opposition. We found no clear definitions within the literature on change management, so have chosen not to define the terms closely but to use both to explore healthcare staff's perceptions of opposition towards change.

The study reported here forms part of wider research that we are conducting into the spread and sustainability of service improvement within two national programmes, the National Booking Programme (NBP) and the Cancer Services Collaborative (CSC) (boxes 2 and 3). Both programmes have attracted significant government funding and are central to its overall strategy to modernise the NHS. The aim of the wider research is to identify factors that help or hinder the spread and sustainability of new practices in the NHS, exemplified by the experiences of these two programmes. Anecdotal evidence suggested that project staff and others have encountered varying degrees of scepticism and resistance and that this has significantly affected the 


\section{Box 1 The NHS improvement agenda}

- The government's vision for the future of the National Health Service (NHS), set out in the NHS Plan of 2000, describes a modern health service that is effective, efficient, and responsive to growing consumer demand. This vision requires changes to the way in which care is delivered, ensuring that it is grounded within a culture that puts the needs of patients and carers first. One of the key components of this move to modernise health care is the need to redesign the way services are organised and delivered so that they work better for patients and staff. Healthcare staff are being supported in this by the NHS Modernisation Agency.

implementation of improvements. We therefore decided to explore this topic as a separate but related element of the main study.

The objective of the study reported here was to explore scepticism and resistance towards changes in working practice associated with two national programmes of service improvement within the NHS in England. Two questions formed the focus of the enquiry:

- Why are some people sceptical or resistant towards these improvement programmes?

- What influences them to change their minds?

\section{METHODS}

A qualitative approach was used to sampling, data collection, and analysis.

\section{Sampling}

In selecting the sample our aim was to gain access to what Bryman describes as "key informants"13 14 - that is, people who have inside knowledge of the study topic, are well informed, and are regarded as "movers and shakers" within the context of the study.

The sample was divided into two distinct groups (box 4). Participants in group 1 were selected purposively and stratified by geographical area, role, and programme. The total number from both programmes was 34 ( 15 doctors and 19 managers). All held national or regional positions and were involved to varying degrees in spreading and sustaining the benefits of the programmes. The profile of this group included at least one person from each section of the programmes' teams, and was countrywide. It therefore represented a cross section of the most senior medical and

\section{Box 2 The National Booking Programme (NBP)}

- The National Booking Programme (now the National Booking Team) is a key component of the government's strategy to modernise the NHS and to make it more accessible to patients. It aims to let patients in England choose and pre-book the date of their healthcare appointment or admission. Launched in 24 pilot sites in 1998, it has expanded to involve every hospital, mental health and primary care trust in England. It is planned that by December 2005 patients will be able to choose booking dates for all hospital appointments and admissions. This will be supported by electronic booking processes throughout England.
Box 3 The Cancer Services Collaborative (CSC)

\section{Improvement Partnership}

- The Cancer Services Collaborative Improvement Partnership is a national programme designed to improve the way in which cancer services are provided. Modelled on the "Breakthrough" approach developed by the Institute for Healthcare in the United States, it offers practical approaches to delivering the government's improvement targets for cancer care. The programme encourages local teams to assess their own services and supports them to make significant improvements by redesigning the way in which care is delivered. Launched in 1999 in nine pilot sites and with five tumour areas, it now encompasses all 34 cancer networks in England.

managerial staff involved with planning and delivering the two programmes.

Group 2 comprised five consultant medical staff who held clinical lead positions within the CSC. They were selfconfessed former sceptics whose earlier views were widely known throughout the CSC community, but who had latterly changed their minds and were prepared to discuss this. They were selected in discussion with members of the national team. Doctors in both groups were all practising consultants (with the exception of one who was a general practitioner). All participants were contacted initially by the programmes' directors; none declined to take part.

While it would have been valuable to include current sceptics in the sample, we chose not to because of the practical difficulties in identifying people of that frame of mind who would be willing to be interviewed.

\section{Study design}

This study was undertaken in the first half of 2002. Semistructured, face-to-face individual interviews were conducted using prepared interview guides. The extent of questioning on the topic of scepticism differed between the two groups.

\section{Box 4 Research sample}

\section{Group 1}

- National Booking Programme:

- 3 lead clinicians

- 10 managers

- Cancer Services Collaborative:

- 12 lead clinicians

- 9 managers

(Questioned about scepticism and resistance within the broader study on spread and sustainability of new practices).

\section{Group 2}

- Cancer Services Collaborative:

- $5^{*}$ lead clinicians

(Interviewed solely on the topic of scepticism and resistance, see Appendix).

- Total for both groups $=39$

*One clinician was interviewed twice, once in each group. 
Participants in group 1 were asked a single question on their experience of scepticism and resistance within an interview for the larger research study. The five lead cancer clinicians in group 2 were interviewed wholly on the topic of scepticism and resistance, questions focusing on their own former opinions, the circumstances of their "conversion", their experience of colleagues' scepticism, and their overall opinion of the CSC programme (see Appendix). Interviews for both groups lasted approximately 1 hour.

\section{Analysis of data}

Interviews were recorded and transcribed. All transcripts were checked by the person undertaking the interview and analysed manually by the lead researcher; a proportion were also analysed independently by another member of the research team. Themes were then compared and contrasted, a process that increases rigour and encourages richer analysis. ${ }^{15}$ The method used was template analysis, an approach in which codes representing themes are identified in the textual data and organised hierarchically to permit analysis at varying levels. ${ }^{16}$ Template analysis is a flexible technique that occupies a position between content analysis and grounded theory. Some themes are identified a priori, corresponding with topic areas contained within the interview guide, but further themes emerge and are coded as analysis proceeds. In using this method our perspective was closer to a grounded theory approach than to content analysis, and we did not count numbers of responses. For this study the question about scepticism contained in the group 1 interviews was extracted and analysed separately from those in group 2.

We did not request ethics committee approval for this study because all participants had contractual arrangements with the NHS Modernisation Agency through their involvement with the two programmes. They were therefore considered to be internal staff whose voluntary involvement in the study could be interpreted as an extension of their remit to promote implementation of the programmes. We were, however, mindful of the need to meet ethical standards of conduct, and followed a set of ethical principles agreed with our academic advisers. These related to issues of informed consent, the right to withdraw, anonymity of sources, and confidentiality of data.

\section{RESULTS}

The results from the total sample (groups 1 and 2) are presented together. The principal themes were the nature and prevalence of scepticism and resistance, its sources, and the process by which staff became supporters of the programmes. They are summarised in a simplified template:

- Nature and prevalence

- Fragility of support

- Sources

- Contextual

- Promotional

- Personal

- Process of change

- Speed of change

- Reasons for change

- Influencing techniques

- Positive aspects

There was some variation of findings within the two groups but these were largely of emphasis and were not great enough to be considered conflicting.

\section{Nature and prevalence of scepticism}

All but one of the participants was able to give examples of scepticism and/or resistance among colleagues. Examples related principally, but not exclusively, to medical staff. Opposition by administrative staff was mentioned only by NBP participants. Several of the CSC clinical leads in group 1 cited themselves as former sceptics.

NBP participants in particular referred to scepticism and resistance as being widespread and difficult to manage. Only one participant from this programme expressed the view that clinical scepticism was not a problem. In contrast, there was relatively little mention among CSC participants regarding the extent of scepticism. The key role of doctors in influencing change was emphasised:

"You can have all your managers on board, all your clerks, nursing staff, allied health professionals ... but if your consultant staff aren't on board then it ain't going to work. Like so many things in the NHS, they are the lynchpin." (Interview 4, Manager, NBP)

\section{Fragility of new support}

Participants said that continuing evidence of improvement was central to the process of securing and maintaining engagement. Sceptics become converted through practical involvement which engages them further in the process of change. However, participants' experience is that new supporters are likely to need proof quickly, and that positive talk cannot replace tangible evidence of improvement. In the early stages of the CSC the programme could only offer hypothetical examples of improvement, and lack of real case studies limited clinicians' interest. There was also a perception among a few participants that staff expected the programmes to deliver more than they had, and that this had led to some disillusionment. It is not yet possible, for example, to draw conclusions about the relationship between service improvement and mortality, and for some critics this limits its value.

There was evidence of continuing reservation, if not scepticism, among even those in group 2. One doctor said that his scepticism was increasing because he was concerned about issues of ownership and data collection. Concerns about the speed of implementation and impact on the treatment of other conditions were highlighted, leading another to comment that he regarded himself "as a real champion with certain conditions attached". Clearly, if support begins to decline among key staff, this will affect long term sustainability of the programmes.

\section{Sources of scepticism and resistance}

In discussing the sources and circumstances of scepticism and resistance, participants in both groups highlighted several factors which have been grouped into subthemes as contextual, promotional, and personal factors.

\section{Contextual factors}

Participants in both groups expressed a belief that the political and organisational context within which the programmes operate contribute to scepticism. There were already numerous national initiatives and targets to be addressed, and performance targets in particular were seen to take organisational priority over programmes of service improvement. The implication of this distinction between performance and service improvement is that they are separate activities of unequal importance. Scepticism towards improvement programmes arose because some managers and clinicians viewed them as diversions from the principal focus of attention-the achievement of targets.

There was a perception that national programmes were imposed by government or senior managers and that ordinary staff had little opportunity to influence plans. This 
perceived "top down" approach led to a belief that changes are transient and founded on political whim. Several participants said that they knew colleagues who were sceptical towards all new government health service initiatives, irrespective of their objectives.

There was also evidence that some resistance towards the CSC arose from opposition to the perceived aims of the programme itself. Some participants explained that colleagues believed the focus of so much extra resource and time on cancer services above other clinical areas to be inappropriate and inequitable.

"What makes people sceptical is [that] this is seen as another little management idea ... it's just another whim and it will go away. To try and deal with that on top of the 200 and whatever other national priorities people have got to deal with ... is just too much for them to take in sometimes." (Interview 9, Manager, NBP)

"One area of resistance is that some people see the focus on cancer as being detrimental to other areas of the department. One of my colleague's first response was to start doing an audit to show that all his 'stone' patients were suffering as a result of this emphasis on cancer work." (Interview 37, Clinical lead, CSC, describing the response of a urology consultant)

\section{Promotional factors}

The way in which both programmes were initially promoted contributed significantly to scepticism and resistance. Many participants in group 1 described how they had encountered considerable misunderstanding about aims, methods, and benefits. Within the NBP this was the most frequently perceived cause of scepticism. Booking was viewed as simply an extension of the current system of giving patients appointment dates rather than as a fundamental system of process redesign. Since it was seen as a change to administrative processes, senior clinical and managerial staff could not always understand why they needed to be involved at all. A programme which aims to give patients choice about their appointment dates was not regarded as having the same attraction for clinical staff as one that impacts on specific diseases. Attempts by project managers to involve clinical and other staff were therefore commonly resisted, at least initially:

"[He] decided he didn't want to be involved at the beginning; thought booked admissions was just about what he had been doing all his life, just giving patients dates really, not redesigning the process and looking at capacity and demand." (Interview 25, Manager, NBP)

"I have trouble with it even with senior clinical managers in this hospital. They say, 'What on earth is this nonsense? Can't you just do it in your spare time? Why don't we leave that to the girls in outpatients?"' (Interview 2, Clinical lead, NBP)

All but one of the lead clinicians in group 2 traced their former scepticism to the way in which the CSC had been introduced to them. At the outset some had expressed doubts about the concept but were curious enough to want to learn more about how it worked in practice. However, their scepticism was fuelled by their first exposure to the methodology and language presented to them at the launch of the CSC in the UK. The style and content of presentations, with unfamiliar theory and lacking real clinical examples, did not engage them. They felt strongly that the initial approach should have focused on practical examples of benefit. A lead clinician also indicated that he would have been more receptive if the message had come from one of his peers, someone recognised as having "authority or clout" among the medical community.

Although discussion of the event by participants was largely negative, they also had positive reflections. It acted as a catalyst for them, fuelling their curiosity and determination to become actively involved in shaping the programme's implementation. Many of these vocal sceptics went on to become strong advocates of the programme over time.

\section{Personal factors}

Participants in both groups expressed the belief that some staff resist change for complex personal reasons. A lead clinician in group 2 spoke about "perverse incentives" that lead some doctors to resist changing the current system, interpreted as an allusion to the fact that the longer waiting lists of an "unmodernised" system help maintain demand for private health care. This accords with the findings of Ham et al whose recent evaluation of booking from 1999 to 2001 also found that some clinical opposition to the programme stemmed from a fear that opportunities to treat patients privately would be reduced. ${ }^{1}$

Personal reasons, including fear of loss of power, autonomy or change of role were described in relation not only to consultant medical staff, but also to administrative and secretarial staff. There was evidence of a disinclination to change systems that had been built up over time. In some cases, staff had spent years developing processes and systems that were felt to suit them and their patients; to contemplate change was an admission that existing arrangements were inefficient. This would reflect poorly on the person who had developed the system.

Some medical participants expressed the opinion that doctors currently face challenges to their autonomy from government, managers, the media, and a more informed public. They believe that this is contributing to a prevailing air of scepticism and a disinclination to embrace further change. Davies and Harrison assert that, throughout the history of the NHS, doctors rather than managers have held dominant and pervasive influence but that, over the last decade, managers have been able to implement substantial restructuring of clinical services with or without the agreement of doctors. ${ }^{17}$ This has led to a feeling among both groups that the important power lies elsewhere, with a degree of disempowerment being felt on both sides.

"I think that one of the barriers is that people feel threatened. It's just that they might feel that their power has diminished and they don't like that." (Interview 16, Clinical lead, CSC)

"He had worked on a system for 10 years, he was obsessed with perfection and getting it correct, and [he] said, 'Your system cannot be better than mine and I'm not going to change'." (Interview 10, Manager, NBP, discussing the reaction of a clinical colleague)

\section{Process of change}

Participants in both groups described how staff became engaged with the programmes, changing their attitudes and behaviour in the process. Those in group 1, discussing their experience of others, talked of how initial resistance gradually gave way to a sceptical willingness to try the proposed change, followed by acceptance and active involvement. Sometimes new "converts" became champions of the programmes; indeed, this was the case for the five lead clinicians in group 2.

\section{Speed of change}

Most participants, particularly those in project management roles, said that the process of influencing colleagues' attitudes was one that took a considerable amount of time and effort. They described the process of change as one that required persistence, demanding that they "chip away very slightly, week by week, month by month".

However, there was also evidence that single events could have a significant affect in engaging sceptics. Doctors in group 2 spoke extremely positively about process mapping, a team exercise that details how a "typical" patient moves through the system, revealing where delays and duplication 
occur. Although it took time for them to become fully convinced of the benefits of the programme, involvement in process mapping seemed to provide the trigger. It was the surprise element of the process that affected them most, demonstrating their ignorance of the complete patient experience:

"Process mapping was [what] really persuaded me because we all thought we knew what happened to patients when they left our consulting room, but we didn't ... it was an eye opener." (Interview 17, Clinical lead, CSC)

\section{Reasons for change}

Participants in both groups described a number of reasons to account for changes in attitude and behaviour. Most concerned having the benefits of change made real, understood as the most powerful of a range of factors influencing people's readiness to accept change. ${ }^{18}$ As anxieties were allayed and understanding of the programmes grew, so did acceptance. Rogers terms this a "reduction of uncertainty" that increases the likelihood of adoption. ${ }^{19}$ For example, discovering that the required changes could actually be quite small eliminated some resistance:

"They had no idea what actually went on. It was only by getting them to understand, they then started to think: 'Actually, this isn't much of a change for us, it's more of a formalising of what we do already'." (Interview 4, Manager, NBP)

The starting point for some involved them admitting that there were problems with the current service and seeking help from peers. In some instances staff were faced with seemingly intractable problems for which any solution would be tried:

"He knows about the work I've done and said: 'Can you come and talk to us?' It was clear from the problems he was alluding to [that] they had got to do something. That's an example of someone who has been resistant but has heard about it, and out of the situation of chaos and crisis he has said: 'Can you come and help?"' (Interview 21, Clinical lead, CSC, describing a colleague's reaction to the CSC)

Some participants in group 2 recalled having been attracted by the funding that involvement with the CSC brought to trusts. They also foresaw that the programme would expand and that this would necessitate their involvement at a later stage; they therefore decided to take the opportunity to influence it by positioning themselves on the inside rather than remaining apart

\section{Influencing techniques}

Participants in both groups described ways in which they succeeded in influencing colleagues to change. Fundamental to this was the ability to understand the cause of scepticism or resistance for each person, to gauge readiness to change, and to use tailored tactics designed to engage and support. It was described as a skilled process, requiring time and persistence.

Strategies for engagement involved finding the right "hook" and could be either overt or covert. Overt strategies included the presentation of outcome data, the promise of new equipment, or demonstration of a particular tool or improvement technique. Such strategies appeal to what Ham et al refer to as "extrinsic and intrinsic incentives and desires"-for example, the extrinsic incentive of new equipment matched with the intrinsic desire of doctors to offer high quality services. ${ }^{1}$ The need for change facilitators to possess the right skills to identify these should not be underestimated. In addition, it is clearly important for managers to have access to relatively small budgets, enabling them to meet extrinsic incentives. With regard to the use of particular improvement techniques, skill is required in choosing them. Although process mapping was spoken of widely in very positive terms, one participant warned against its overuse, saying that it can make people feel uncomfortable and exposed when it highlights the practice of individuals to large group scrutiny.

Covert ways of gaining support were described. One involved purposively leaving sceptics to weigh up the benefits, allowing them to change their minds in their own time:

"When he saw what had happened in terms of organising a clinical workload more efficiently he came knocking at my door, saying: 'Why have you left me 'til last?' I said: 'Because you chose to be last'." (Interview 25, Manager, NBP)

Recognising that the terminology associated with the programmes could engender further hostility, some project managers chose to omit all references to specific improvement initiatives when making the initial approach:

"I didn't tell them it was a project ... that we were using a methodology. Just went in and said, 'Why don't we try this on one patient?' and it wasn't until we'd started getting change and they [were] getting interested that I started slipping it in about what this was." (Interview 9, Manager, NBP)

Some project leaders carefully placed sceptics among groups of enthusiasts at meetings so that peer influence could take effect. Failing everything, changes could be implemented without the active support of senior staff, but this was not regarded as the preferred way of working:

"You have to work on them one by one and do ... a lot of tiptoeing, talking nicely. Sometimes you can implement booking without them feeling anything, but more often than not we like to work with them'." (Interview 6, Manager, NBP)

Participants in group 2 indicated how they had initially been influenced to become involved even though they remained sceptical for a while. Several had been invited by members of the national team to become clinical leads for the programme, and the honour and professional pride associated with that overrode any continuing misgivings. The national team was undoubtedly aware that these were key opinion leaders, and understood the importance of gaining their active support at an early stage.

\section{Positive aspects of scepticism}

A few CSC participants in group 1 spoke positively about scepticism. They viewed it as an understandable and welcome response to change, challenging project facilitators to reflect on their own opinions and plans. It was described as "reasonable and healthy", one manager commenting that it is "important to have sceptics ... they make you touch base, question yourself". However, most participants did not share this opinion. They described their experiences of challenging scepticism in far less positive terms, likening it to conducting "a war of attrition". Organisational change theory may welcome resistance as a useful ingredient of change, ${ }^{10}{ }^{11}$ but there is little evidence from this study that those leading healthcare modernisation share this view.

\section{DISCUSSION}

These findings confirm that organisational change requiring people to think and behave in different ways is far from straightforward. Kanter et $a 2^{20}$ observed that organisations cannot simply be "ordered" to change. Clearly, not all healthcare staff are convinced of the value of large scale national improvement programmes. While not actively opposing their progress, some are not engaging with them. The reasons for this are complex and relate to contextual, promotional, and personal factors. Staff need time away from their normal duties to consider proposed change, and facilitation and support to make it happen. Not surprisingly, those who have been influenced to become involved need continuing evidence that the new way of working is really a 
better one. The importance of feedback in maintaining commitment to change has long been recognised..$^{21}$ It has been suggested that healthcare managers should use targeted mechanisms, both formal and informal, to meet individual needs. ${ }^{22}$ These could include sharing positive feedback from patients or highlighting improved performance data.

The findings of our broader study into spread and sustainability confirm that support, active engagement, and leadership at senior levels from both doctors and managers are crucial to the long term success of improvement initiatives. ${ }^{23}{ }^{24}$ As managers begin to experience how service improvement helps the attainment of performance targets, their support is likely to increase. Gaining the support of larger numbers of medical and other groups of staff presents more of a challenge. A recent evaluation of the fourth wave of the NBP reveals that resistance continues to impede progress, and that engaging clinicians in particular remains a significant issue. ${ }^{25}$

We found little evidence to support the view that scepticism and resistance should be welcomed; indeed, the dominant perception was that it represents a threat to progress and must therefore be overcome. Yet the positive interpretation adopted by other organisations offers an alternative from which the NHS might learn. Considering scepticism and resistance as indicators of concern and uncertainty turns the focus away from confrontation and towards seeking a shared understanding of the value of change. There are opportunities for learning on both sides of the debate, but these will not be fulfilled within a climate that regards scepticism simply as a problem to be overcome.

This research focused on the early stages of the programmes; lessons have been learned and modifications made, demonstrating a readiness to meet the concerns of sceptics. Both programmes have changed the style and content of promotional events and improved their systems of data management. Using trusted credible sources to spread the improvement message is known to increase adoption and spread. ${ }^{18} 26$ The programmes recognise this and have now expanded their clinical lead networks.

\section{Implications of the findings}

Considerable time is being spent persuading sceptics to become supporters. To some extent this is succeeding but the widespread engagement of staff has not yet occurred and is slowing the potential impact of modernisation. These findings show that scepticism and resistance towards organisational change are complex and multifactorial issues. There is no simple formula for managing them. Healthcare leaders need to be aware of the prevalence of scepticism and resistance, understand its impact and value, and to promote change in ways that appeal to the individual if they are to succeed in moving the improvement agenda forwards. The opinions and behaviour of doctors are particularly important, and their support is vital.

\section{Limitations of the research}

The research sample was relatively small and comprised only senior staff from two improvement programmes. It could be argued that their opinions offer only a partial account of the extent to which scepticism and resistance hamper change and that, as senior leaders, their experiences are different from those of frontline staff. However, participants were selected because they were believed to be key informants. The majority, both clinical and managerial, were closely in touch with acute trust staff; indeed, the doctors in the sample were practising clinicians as well as change leaders. It is therefore likely that their views do reflect the opinions of a broader constituency. The consistency of the responses also counters the limitations of small sample size.
Key messages

- Scepticism and resistance among key staff affect the implementation and spread of new practices in the NHS.

- The causes of scepticism and resistance are complex and include objections to the nature and substance of new practices, the way in which they have been introduced, and personal reluctance to change.

- Support for change can be gained by the use of tailored influencing techniques, but may remain fragile and dependent on continuing evidence of benefits.

It must also be acknowledged that participants may have been careful to present themselves as champions of the programmes, particularly since they held senior positions within them. This is recognised as a valid criticism of the use of interviews in qualitative research, ${ }^{27}$ but the authors believe it to be an appropriate method for researching issues that cannot be easily observed, and have striven to take account of the context in which the data were produced.

This research also forms the first stage of a longer study that continues to explore the factors affecting the spread and sustainability of service improvement. The use of a range of methods and approaches will offer the opportunity to add further to the findings reported here.

\section{ACKNOWLEDGEMENTS}

The authors thank the staff from both programmes who agreed to be interviewed for this research and the reviewers for their helpful comments on earlier drafts.

\section{Authors' affiliations}

R Gollop, E Whitby, D Ketley, Research into Practice Team, NHS

Modernisation Agency, Leicester, UK

D Buchanan, Leicester Business School, De Montfort University, Leicester, UK

Conflicts of interest: none.

\section{APPENDIX: INTERVIEW GUIDE FOR "SCEPTICS TO SUPPORTERS" INTERVIEWS (GROUP 2)}

\section{Questions}

- What is your role within the CSC (locally and nationally)?

- How long have you been involved?

- I know that you were originally somewhat sceptical about the Programme, but that you're now a supporter. Could you tell me about your original scepticism-why did you feel like that?

- Could you tell me how the change to becoming a supporter came about? What was it that made you change your mind? Were there any specific events or meetings, for example, which led you to change your mind? Can you tell me about what happened?

- Can you remember what else was going on in your Trust at that time (other changes, external pressures, etc)? Do you think that was connected in any way to you changing your mind?

- What about your colleagues/other key players-what were their opinions of the Programme?

- How do you think people who are sceptical or resistant can be influenced to think again about the Programme?

- Is there anything else you'd like to add about scepticism or resistance that you think is important? 


\section{REFERENCES}

1 Ham C, Kipping R, McLeod H. Redesigning work processes in health care: lessons from the National Health Service. Milbank Quarterly 2003;81:415-39.

2 Edwards N, Marshall M. Doctors and managers. BMJ 2003;326:116-7.

3 Locock L. Healthcare redesign: meaning, origins and application. Qual Saf Health Care 2003;12:53-8.

4 Shekelle PG. Why don't physicians enthusiastically support quality improvement programmes? Qual Saf Health Care 2002;1 1:6.

5 Morrison PE, Heineke J. Why do health care practitioners resist quality management? Qual Prog 1992;25:51-5.

6 Locock L. Maps and journeys: redesign in the NHS. Birmingham: Health Services Management Centre, University of Birmingham, 2001.

7 Prochaska JM, Prochaska JO, Levesque DA. A transtheoretical approach to changing organizations. Admin Policy Mental Health 2001;28:247-61.

8 Plsek P. Spreading good ideas for better health care: a practical toolkit. USA: VHA Publishing, 2000.

9 Plsek P, Kilo CM. From resistance to attraction: a different approach to change. Physician Exec 1999;25:40-2.

10 Schon DA. Champions for radical new inventions. Harvard Business Rev 1963;March/April:77-86.

11 Wadell D, Sohal AS. Resistance: a constructive tool for change management. Manage Decision 2001;36:168-91.

12 Wilcock $\mathbf{P}$, Lewis A. Putting improvement at the heart of health care. BMJ 2002;325:670-1.

13 Bryman A. Research methods and organization studies. London: Routledge, 1989.

14 Bryman A. Social research methods. Oxford: Oxford University Press, 2001.
15 Barry CA, Britten N, Barber N, et al. Using reflexivity to optimise teamwork in qualitative research. Qualitative Health Res 1999;9:26-44.

16 King N. Template analysis. In: Symon G, Cassell C, eds. Qualitative methods and analysis in organisational research. London: Sage, 1998.

17 Davies HTO, Harrison S. Trends in doctor-manager relationships. BMJ 2003;326:646-9.

18 Berwick D. Disseminating innovations in health care. JAMA 2003;289:1969-75.

19 Rogers EM. Diffusion of innovations. 4th ed. New York: The Free Press, 1995.

20 Kanter RM, Stein BA, Jick TD. The challenge of organizational change. New York: The Free Press, 1992.

21 Kotter J. Leading change. Boston: Harvard Business School Press, 1996.

22 Narine L, Persaud DD. Gaining and maintaining commitment to large-scale change in healthcare organizations. Health Serv Manage Res 2003;16:179-87.

23 NHS Modernisation Agency. Sustainability and spread in the National Booking Programme. Research into Practice Summary Report No 2. NHS Modernisation Agency, 2002.

24 NHS Modernisation Agency. Spreading and sustaining new practices: sharing the learning from the Cancer Services Collaborative. Research into Practice Summary Report No 3. NHS Modernisation Agency, 2002.

25 NHS Modernisation Agency. National Booking Programme-4th wave evaluation. Research into Practice. NHS Modernisation Agency, 2003.

26 Dopson S, Fitzgerald L, Ferlie E, et al. No magic targets! Lessons from UK studies of attempts to change clinical practice to become more evidence based. Health Care Manage Rev 2002;27:35-47.

27 Murphy E, Dingwall R, Greatbach D, et al. Qualitative research methods in health technology assessment: a review of the literature. Health Technol Assess 1998:2(16). 